\title{
The Effect of Virtual Users' Autonomous Social Behavior on Atypical Architectural Design in the Design Studio
}

\author{
Yun Gil Lee \\ ${ }^{1}$ Associate Professor, Department of Architecture, Hoseo University, Republic of Korea, \\ yglee@hoseo.edu
}

\begin{abstract}
Recently, user behavior simulation for atypical buildings is becoming increasingly important due to social demand. This provides an environment in which users can observe user's behavior that is easily overlooked in the atypical architectural design process. It is necessary to reproduce social phenomena as well as reaction behaviors in an atypical physical space in order to construct a successful human behavior simulation for an atypical architectural space because the behavior of users in the architectural space entails a social response. Through previous research, ActoViz - which was developed to simulate user behavior in the atypical architecture-improved and human-shaped agents were developed to perform social interactions. ActoViz was evaluated positively in discovering creative problem findings of architects through the interaction between the designed atypical space and the agent in the previous study. However, it has not been revealed how social interaction in the designed atypical space affects creative problem findings. Therefore, this study is intended to examine how the automatic social interaction of agents in the atypical architectural design process affects creative problem findings. For this purpose, experiments and questionnaires were conducted to students in the Department of Architecture studio, and the analysis was performed. 35 undergraduate students participated in this experiment, it was conducted in a simulated human behavior atypical design process and a questionnaire. A paired-sample t-test was used to analyze the survey results. The experimental and questionnaire results found that social behavior simulation was statistically effective in designing a new atypical form, designing various functions, and designing an appropriate atypical form. The results of the experiments and questionnaires found that social behavior simulation was statistically effective in designing a new atypical form, designing various functions, and designing an appropriate atypical form.
\end{abstract}

Keywords: Social Behavior, Virtual User, Atypical Design, Space, Behavior Simulation

\section{Introduction}

Recently, there is an increasing social demand for user behavior simulation for atypical buildings as it is becoming increasingly important. This provides an environment in which users can observe behavior that is easily overlooked in the atypical architectural design process[1][2]. In order to construct a successful human behavior simulation for an atypical architectural space, it is necessary to reproduce social phenomena and reaction behaviors in an atypical physical space because the behavior of users in the architectural space entails a social response. In an atypical space, we can easily observe that people form groups to perform similar actions, imitate others, or engage in social interactions appropriate to physical situations. [Fig. 1] shows the social behaviors of users and their interactions with others in an atypical architectural space. In the architectural space, social behavior appears to

Received: July 13, 2021; $1^{\text {st }}$ Review Result: August 30, 2021; $2^{\text {nd }}$ Review Result: October 16, 2021 Accepted: November 30, 2021 
imitate others or to form a collective consensus. It also appears through social norms. The morphological characteristics of an atypical space can cause unexpected use, which can also affect social behavior.

ActoViz-which was developed to simulate user behavior in the atypical architecture-has improved through previous research, and human-shaped agents were developed to perform social interactions. ActoViz was revealed positively in discovering creative problem findings of architects through the interaction between the designed atypical space and the agent[3]. However, it is unclear how social interaction in the designed atypical space affects creative problem findings. Therefore, this study intends to examine how the automatic interaction of agents in the atypical architectural design process affects creative problem findings.

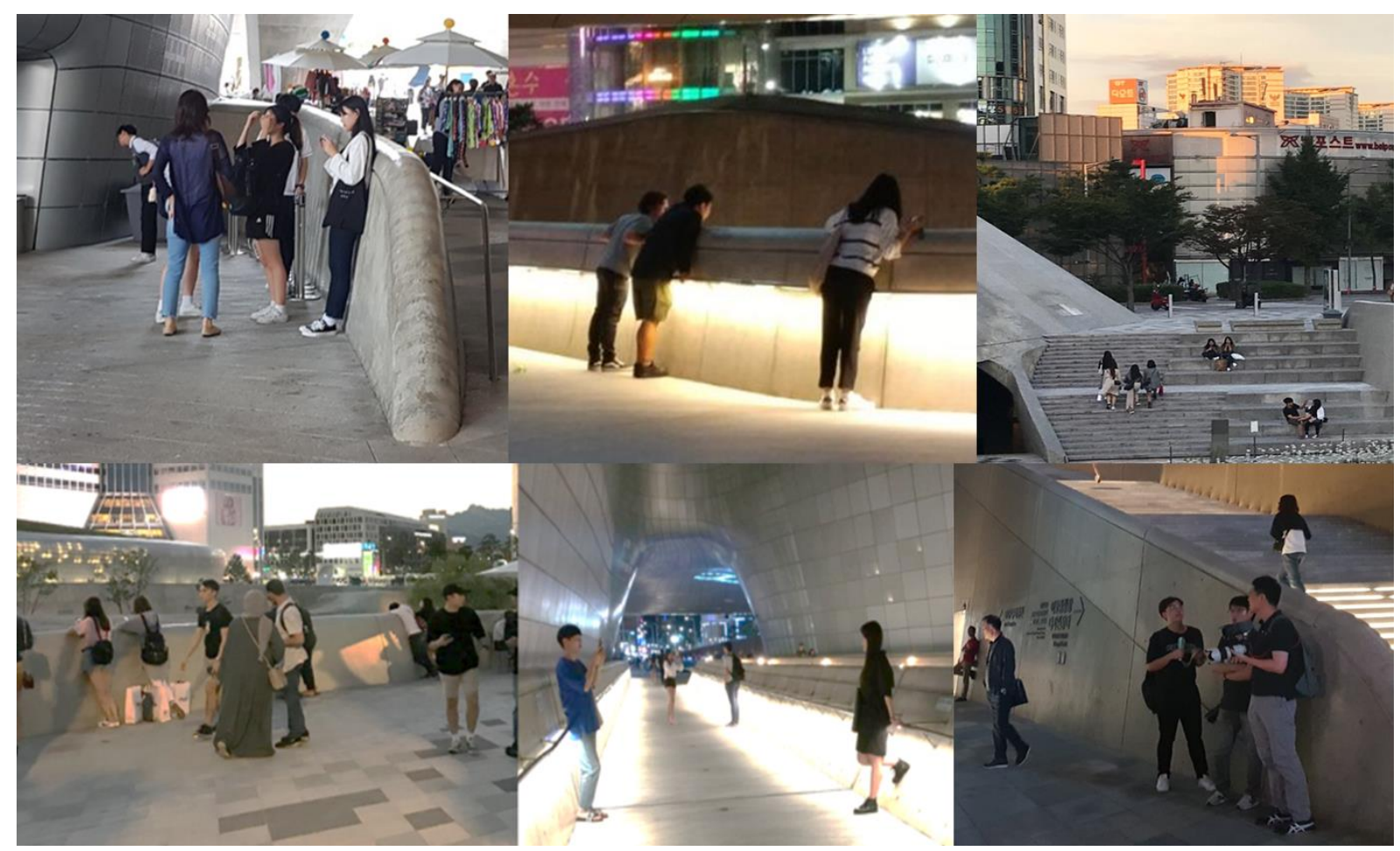

[Fig. 1] Examples of Social Interactions in Atypical Architectural Spaces

\section{Atypical Architectural Design \& Human Behavior Simulation}

Traditionally, during the architectural design process, architects have predicted the performance of the user side of a space by judging the relationship between the space and the user. They do this by superimposing the human figure on the design result and visualizing it. Simulation of human behavior in the field of architecture has been carried out for a very long time[4]. Hong and Lee[5] used a comparative experiment to see how the use of representations depicting human behavior had an effect on idea generation related to novelty and functionality that are both elements of creativity. This is a study on the effect of image-based human behavior simulation that has been conventionally performed or experienced. According to the evaluation of the participating students, reproductions depicting human behavior gave positive help to ideas related to functionality, but had a negative effect on ideas related to novelty. That is, the designer was able to recognize and infer the relationship between the user's behavior and space through the use of human behavior representations. In the results of this study, the designer imagined and predicted stories that could be created in the occupant's experience and space through various actions of human representations. Essentially, the use of representations 
depicting human behavior has the effect of facilitating the designer's ideas about functionality[5].

[Fig. 2] is related to the study of the effects of image-based human behavior simulation in the process of atypical architectural design. In other words, this study shows how human behavior simulation affects the creative problem-solving of atypical architectural design results. According to the results of the study, the visual expression of human behavior in the atypical architectural design process had a positive effect on the students' confidence who evaluated the usefulness and value of the design results. In addition, students were able to find various functions in the design process and had a positive effect on students' confidence in the safety and comfort of users utilizing the design result. Taken together, it was found that expressing user behavior in atypical architectural design had a positive overall effect. In other words, human expression affects the architect's problem discovery and related design development, not only in the existing design field but also in atypical design[3][5].
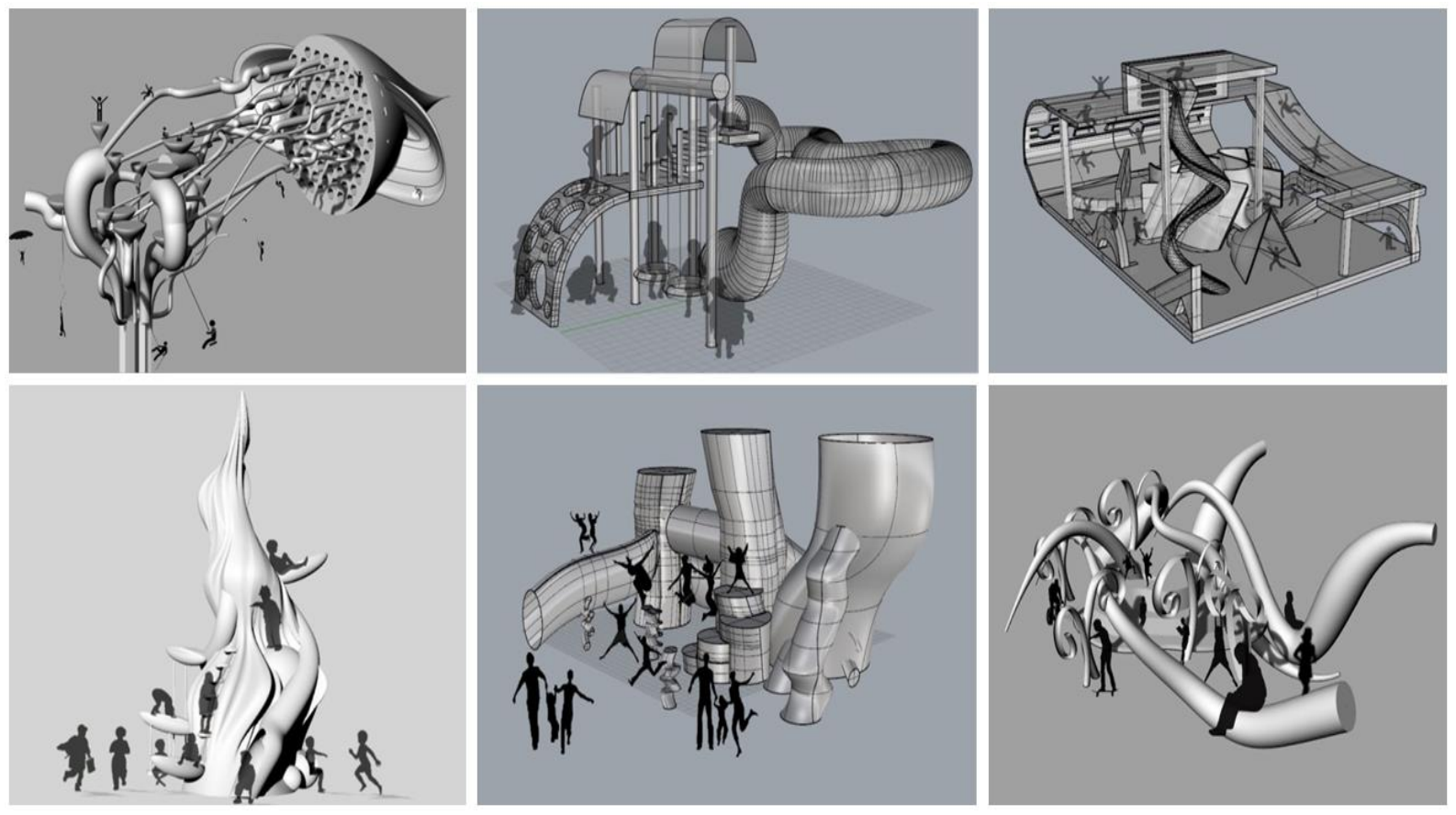

[Fig. 2] Results of Atypical Space Design based on Human-shaped Images (Lee, 2017)[3]

\section{Social Behavior in Atypical Architecture}

The social interaction of users in an architectural space is often seen phenomenon. As humans are social animals, they gain stability in their relationships with others. Social behavior of people are related to psychological stability. To understand the psychological causes of users' social behavior in atypical architectural spaces these behaviors were investigated and analyzed by visiting a representative atypical building where user behavior centered on atypical physical elements was observed and classified into common contents.

Self-Perception, Behavioral Conformity, In-Group Bias, and Behavior Setting were derived by categorizing the classified contents based on psychological evidence. Self-Perception is recognizing one's own state through the actions of others. Behavioral Conformity is a social interaction that imitates the behavior of others. In-Group Bias refers to finding psychological stability by taking actions in the same context in a socially related group. Behavior Setting is the social interaction which the characteristics of physical space and social consensus created. Self-Perception is difficult to 
express visually in simulation through a human-shaped agent. Behavioral Conformity, In-Group Bias, and Behavior Setting can be developed through simulations, they are linked to the physical situation and expressed in detail as user behavior[6-8].

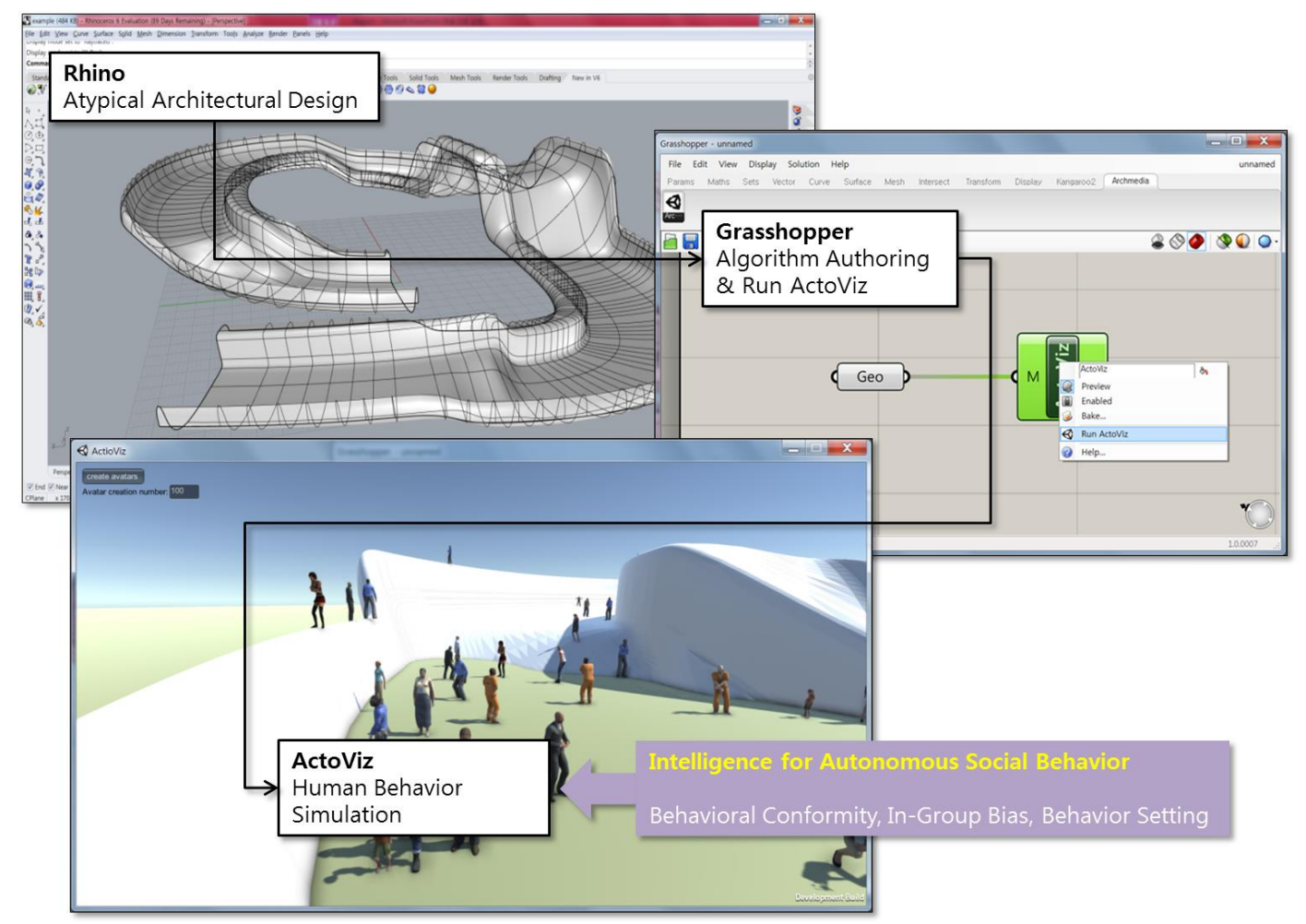

[Fig. 3] Diagram of the Process of using ActoViz and the Introduction of Social Behavior as Agent's Artificial Intelligence

\section{Autonomous Social Behavior Simulation in ActoViz}

[Fig. 3] shows the social behavior simulation environment based on ActoViz. ActoViz is a tool that supports human behavior simulation in the process of atypical architectural design to perform a more appropriate design for users. ActoViz was developed based on Rhino and Grasshopper, which are commercial atypical architectural space design tools. This is to enable real-time human behavior simulation in the atypical design process. ActoViz was developed based on a virtual reality technology called Unity3D. It is a method in which the atypical design is designed through Rhino that is automatically inserted into virtual reality, and a human agent walks freely in it.

The core function of ActoViz is the autonomous behavior technology of a human-shaped agent equipped with artificial intelligence. Previous research discovered that an agent technology that responds appropriately to the physical space was developed, and the effect was studied[3]. In addition, agent technology for performing social interaction was subsequently developed, and this study will reveal its effect.

[Fig. 4] shows the digital modeling of social interaction behavior required to perform human behavior simulation for social interaction in ActoViz. As shown in [Fig. 4], after modeling the entire social interaction situation, it was divided into individual actions and loaded into ActoViz. This was developed to have an appropriate social behavior that can be reproduced according to the agent's position in the simulation process. 


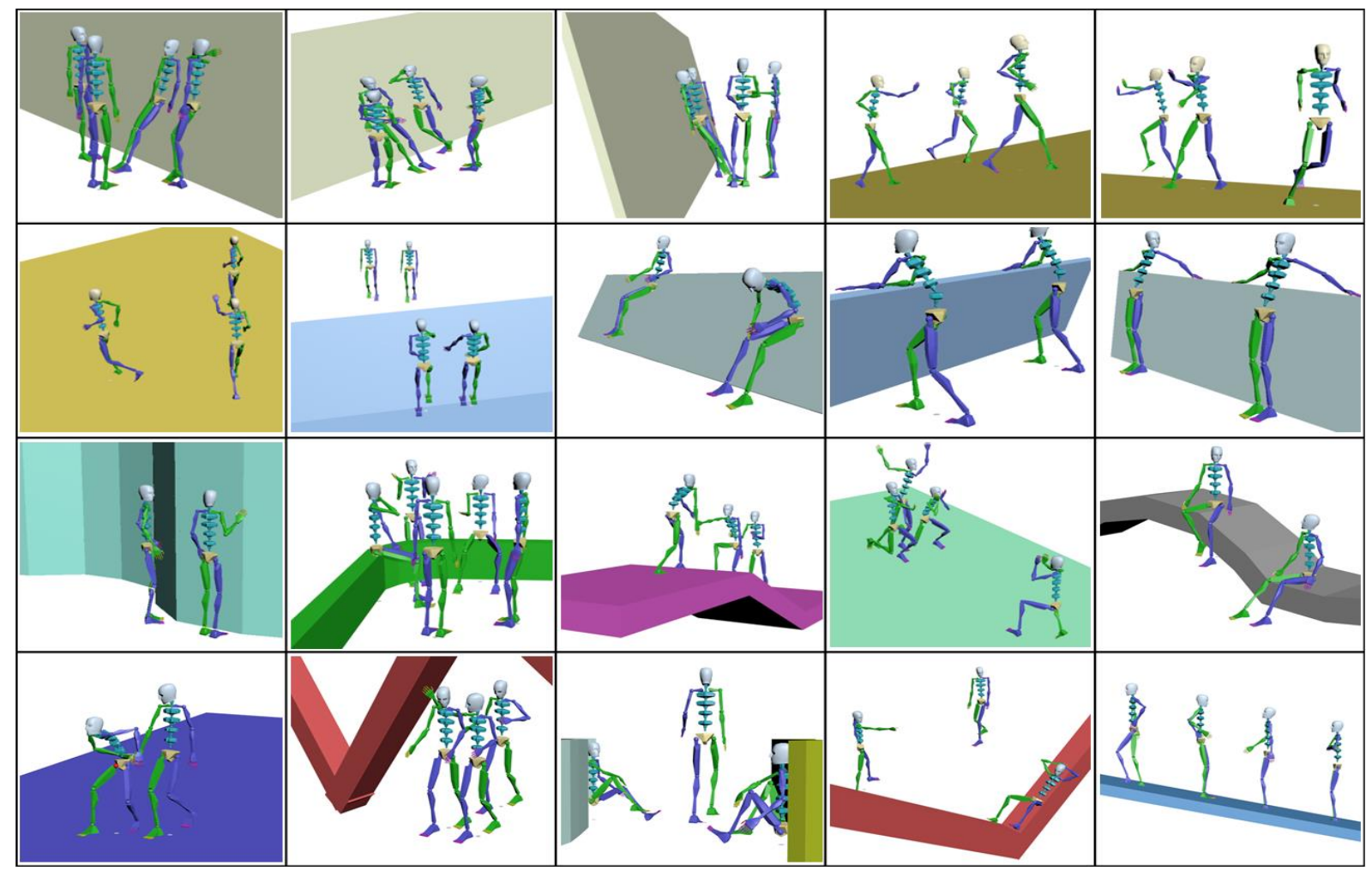

[Fig. 4] Digital Behavior Modeling of Social Behaviors in the Atypical Architecture

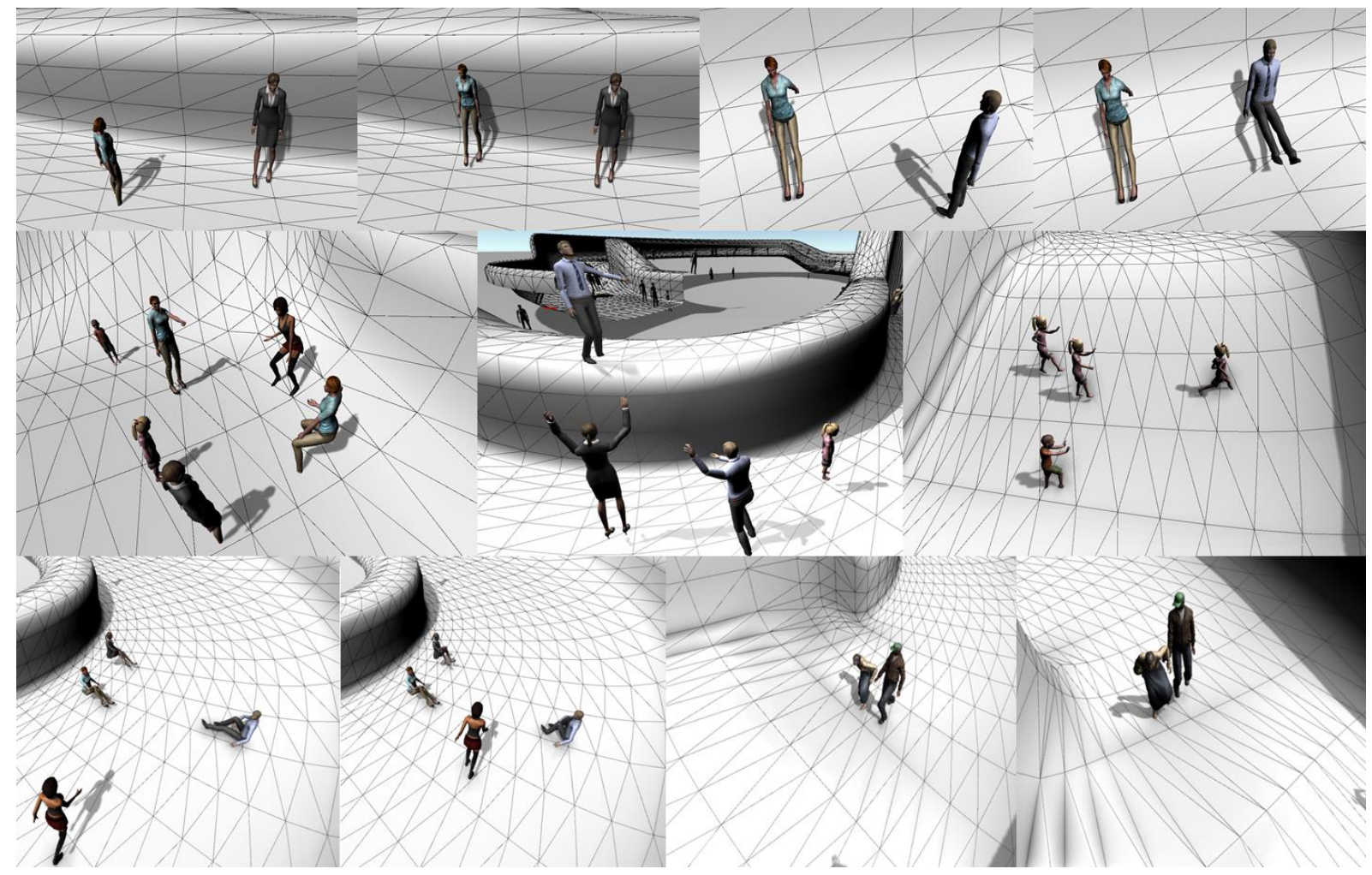

[Fig. 5] Developed Autonomous Social Behaviors of Agents in ActoViz

[Fig. 5] shows autonomous social behaviors for human behavior simulation of an atypical architectural space in ActoViz. In [Fig. 5], the first line shows Behavioral Conformity, the second line shows In-Group Bias, and the third line shows how it is reproduced on ActoViz for Behavior Setting. 
[Fig. 6] describes how an agent's behavior is triggered. By converting the irregular space into voxels, the types of voxels are distinguished, and social behavior is reproduced based on the specified type.

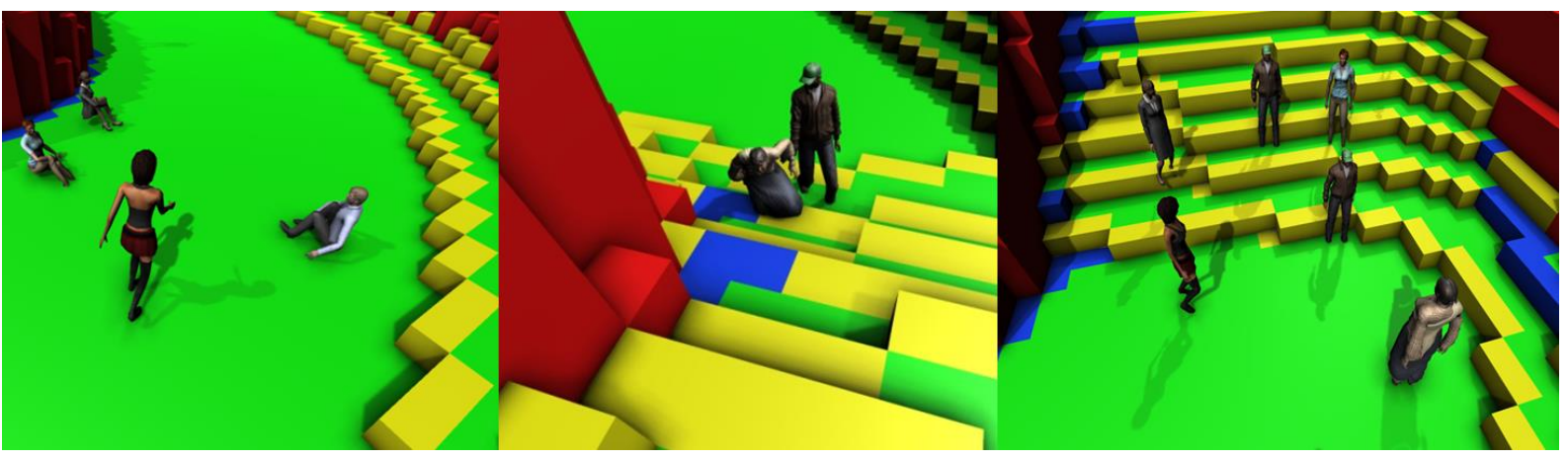

[Fig. 6] Deployment of agent's social behaviors extraction using voxelization

\section{The Effect of Autonomous Social Behavior on Creative Problem Findings in Atypical Architectural Design}

\subsection{Background}

Architectural design is the process of generating creative products. Creativity is an important factor defining an architect's ability. Definitions of creativity are very diverse and broad. In this study, creativity is recognized as the production of new and appropriate efforts to develop creative thinking for students that are continuing in architecture education. The development of creativity can accumulate through personal experience of creative problem-solving or discovery of new things. Therefore, it is very useful for architectural design tools to support creative experiences. Atypical buildings are recognized as more creative products than conventional buildings because of the novelty of the architectural shape. However, as discussed above, it is not easy to review whether a new type of building is suitable for users. Creativity of atypical architectural design requires appropriateness for users along with a new type of design. In this respect, user simulation in atypical tools is meaningful. Previous studies on the overall effect of user simulation in the atypical architectural design process showed several positive effects on creative problem-finding. In this study, the effect of user's social behavior was studied in terms of creative problem-finding[5][9].

\subsection{Method}

During the 2021 Spring Semester, 23 students enrolled in a seminar on computer-aided architectural called Digital Design Lab 1. They were all third-year students at H University in South Korea with a degree in architecture, a five-year technical program. One of the goals of this course is to teach students to create new architectural types using a digital modeling tool. The teacher asked the students to build a playground using different styles of spaces and sculptures that would encourage children to take part in various games. The students used Rhino 3D—a digital modeling tool that allowed them to freely model atypical shapes - to design the playgrounds.

In the classroom, each student built a playground and designed a digital model. They used their own experiences and knowledge to design physical shapes for human use. Next, the students conducted the ActoViz human behavior simulation on their projects. During this human behavior simulation, the social behavior function of ActoViz was switched on and off several times. They have used modeling to define and fix issues in their projects. The students used Rhino and ActoViz several times to 
replicate the modeling process. [Fig. 7] shows students' work for atypical playgrounds designed using Rhino (left) and user simulations in ActoViz (right)[10][11].

After finishing these playground design tasks, the students compared their design results before and after they used the social behavior function to evaluate human interactions with their design. They then responded to a questionnaire about the usefulness of the social behavior function to the design process. The questionnaire used a 7 -point Likert scale $(0=$ not at all; $7=$ very much). The criteria focused on creative problem-finding and included the following statements (the students indicated their agreement or disagreement): (1) The adaptive behavior function helped improve the quality of your atypical spatial design; (2) The function facilitated the process of planning an atypical space; (3) The function increased your confidence in the usefulness/rationality of the final design; (4) The function helped you design new shapes; (5) The function helped you design various functions for the space; (6) The function improved the design's safety and convenience; (7) The function helped you plan an appropriate atypical space; and (8) The function helped you identify problems and design errors. These criteria were based on prevailing creativity principles that were changed to match the context of the given design tasks[12].
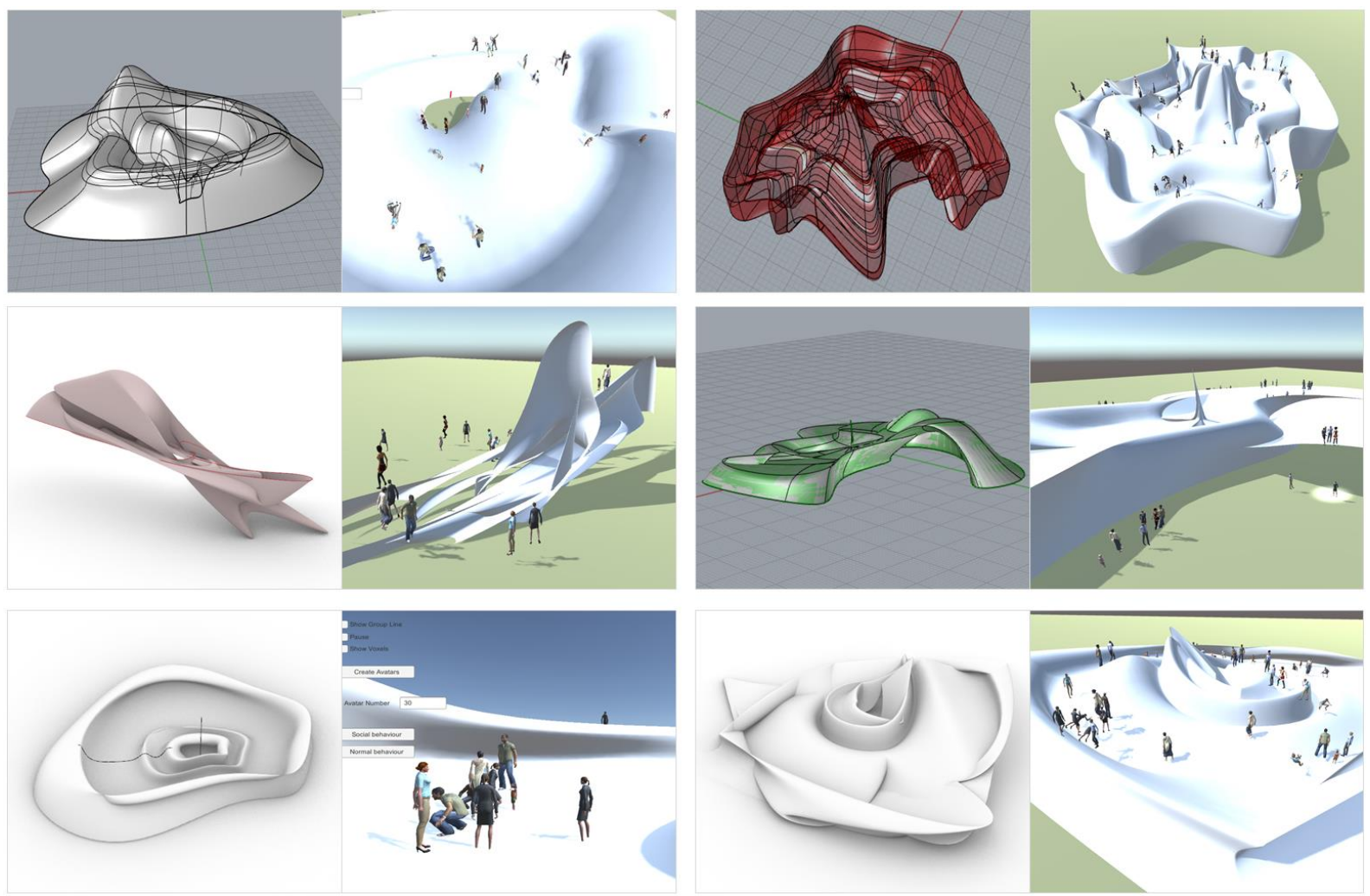

[Fig. 7] Six Students' Work: Atypical Playgrounds Designed using Rhino (left) and Human Simulations with Agent's Social Behavior in ActoViz (right)

\subsection{Results}

A paired-sample t-test accompanied the study to compare student self-assessment scores on the creative problem-finding before and after using the social behavior function to evaluate their designs.

In response to statement (4), the students indicated that they were able to design new shapes after using the social behavior function $(\mathrm{M}=4.61, \mathrm{SD}=1.26)$ than before $(\mathrm{M}=4.17, \mathrm{SD}=1.26 ; \mathrm{t}(23)=-$ $2.328, \mathrm{p}<.030)$. This suggests that the social interaction function helped the new form of design. The 
responses to statement (5) indicated that the social behavior function helped the students find more varied functions for their designs $(\mathrm{t}(23)=-2.859, \mathrm{p}<.009)$. This means that more diverse functional forms could be conceived in the designed design when using the social interaction function. Regarding statement (7), the t-test indicated that, after using social behavior function $(\mathrm{M}=4.78, \mathrm{SD}=1.44)$ helped the students plan more appropriate atypical space than before $(\mathrm{M}=4.22, \mathrm{SD}=1.57 ; \mathrm{t}(23)=-$ $2.418, \mathrm{p}<.024)$. This means that it was possible to judge whether or not the atypical shape that one designed was appropriate through the social behavior function, and to make a more proper architectural alternatives.

Although the results of Statements (6) and (7) are not statistically significant, they've showed that the social behavior function improves the safety and convenience of design alternatives and helps to understand design problems to some extent. However, as Table 1 shows, no statistically significant results were observed in the responses to statements (1), (2), and (3). The analysis data found that the social behavior function did not help the students go through the overall design process or produce appropriate design results.

[Table 1] Paired-samples t-tests on Creative Problem Finding Before and After using the Autonomous Adaptive Behavior Function

\begin{tabular}{|c|c|c|c|c|}
\hline & \multicolumn{2}{|c|}{ Mean (Standard Deviation) } & \multirow[b]{2}{*}{$\begin{array}{c}\text { Mean } \\
\text { Difference }\end{array}$} & \multirow[b]{2}{*}{$\begin{array}{c}\mathrm{P} \\
(* \mathrm{p}<.05)\end{array}$} \\
\hline & $\begin{array}{l}\text { Before Autonomous } \\
\text { Social Behaviors } \\
\quad(\mathrm{n}=23)\end{array}$ & $\begin{array}{l}\text { After Autonomous } \\
\text { Social Behaviors } \\
\qquad(\mathrm{n}=23)\end{array}$ & & \\
\hline $\begin{array}{l}\text { (1) Helped improve the quality of } \\
\text { your atypical spatial design }\end{array}$ & -0.83292 & 0.22422 & -1.194 & 0.245 \\
\hline $\begin{array}{l}\text { (2) Facilitated the process of } \\
\text { planning an atypical space }\end{array}$ & -0.40401 & 0.23009 & -0.569 & 0.575 \\
\hline $\begin{array}{l}\text { (3) Increased your confidence in } \\
\text { the usefulness/rationality of } \\
\text { the final design }\end{array}$ & -0.36744 & 0.10657 & -1.141 & 0.266 \\
\hline (4) Helped you design new shapes & -0.82213 & -0.04743 & -2.328 & $0.030^{*}$ \\
\hline $\begin{array}{l}\text { (5) Helped you design various } \\
\text { functions }\end{array}$ & -0.67514 & -0.10747 & -2.859 & $0.009^{*}$ \\
\hline $\begin{array}{l}\text { (6) Improved safety and } \\
\text { convenience }\end{array}$ & -0.96383 & 0.00731 & -2.043 & 0.053 \\
\hline $\begin{array}{l}\text { (7) Helped you plan an } \\
\text { appropriate atypical space }\end{array}$ & -1.05003 & -0.08041 & -2.418 & $0.024 *$ \\
\hline $\begin{array}{l}\text { (8) Helped you identify problems } \\
\text { and design errors }\end{array}$ & -0.79820 & 0.01559 & -1.994 & 0.059 \\
\hline
\end{tabular}

\section{Discussion}

The experiment and questionnaire results found that social behavior simulation was statistically effective in designing new atypical form, various functions, and appropriate atypical form. This indicates that, through the social interaction shown by the human-shaped agent, architects can obtain design ideas for newer forms and various functions. In addition, it was discovered through questionnaire analysis that previously could not be found in the effect of the physical interaction between the atypical space and the agent. This suggests that social behavior helped design an 
appropriate atypical space. In other words, the social behavior of the human-shaped agent provides a better environment to understand the social situation associated with an atypical space, and through this, it is possible to judge whether it is a more appropriate design or not.

Contrary to these positive effects, there were also negative opinions. Looking at the descriptive answers, many felt that more sophisticated development and technical supplementation were needed. In other words, they answered that it was difficult to distinguish between the social interactions of the agents and those that were not, and that it was rather less realistic because the agents acted in an unusual way. In addition, it was said that it was insufficient to observe people's normal and natural behavior, and the agent's behavioral errors were a hindrance. Future research must improve the agent's behavior and conduct experiments and analyses targeting more subjects.

\section{Conclusion}

This study examined how the automatic social interaction of agents in the atypical architectural design process affects creative problem-findings. For this purpose, experiments and questionnaires were conducted to students in the studio of the Department of Architecture, and an analysis was performed. The experimental and questionnaire results found that social behavior simulation was statistically effective in designing a new atypical form, designing various functions, and designing an appropriate atypical form. In the further research, it is necessary to develop more sophisticated technology. In addition, it is necessary to evaluate and analyze this system for a large number of students.

\section{Acknowledgments}

This work was supported by the National Research Foundation of Korea (NRF) grant funded by the Korea government (MSIT) (NRF-2018R1A2B6005827).

\section{References}

[1] B. Hiller, J. Hanson, Social Logic of Space, Cambridge University Press, (1984)

[2] D. A. Norman, Affordances, Conventions, and Design, Interactions, (1999), Vol.6, No.3, pp.38-43, DOI: $10.1145 / 301153.301168$

[3] Y. L. Lee, Y. G. Lee, A Study on the Effect of Human Factor for Atypical Design in the Architectural Design Studio, Advances in Intelligent Systems and Computing, (2018), Vol.876, No.1, pp.130-134, DOI: 10.1007/978-3-03002053-8_21

[4] R. Imrie, Architects' conceptions of the human body, Environment and Planning D, (2003), Vol.21, No.1, pp.47-65, DOI: $10.1068 / \mathrm{d} 271 \mathrm{t}$

[5] S. W. Hong, Y. G. Lee, A Study on the Effectiveness of Using Human Behavior Presentation on Creative Motivation in Architectural Design Process, Journal of the Architectural Institute of Korea Planning \& Design, (2014), Vol.30, No.3, pp.93-100, DOI:10.5659/JAIK_PD.2014.30.3.093

[6] D. G. Myers, Social Psychology, 11th edition, McGraw Hill Higher Education, (2012)

[7] D. R. Forsyth, Group dynamics, 5th edition, Wadsworth Cengage Learning, (2014)

[8] E. Hatfield, J. T. Cacioppo, R. L. Rapson, Primitive emotional contagion, Emotion and Social Behavior, (1992), Vol.14, No.1, pp.151-177. 
[9] M. A. Runco, Creativity: Theories and themes: Research, development, and practice, Academic Press, (2014)

[10] S. Hong, D. Schaumann, Y. E. Kalay, Human behavior simulation in architectural design projects: An observational study in an academic course, Computer, Environment, and Urban Systems, (2016), Vol.60, pp.1-11, DOI: 10.1016/j.compenvurbsys.2016.07.005

[11] D. Simeone, Y. E. Kalay, D. Schaumann, S. Hong, Modeling and simulating use processes in buildings, Proceedings of Education and Research in Computer Aided Architectural Design in Europe, (2013), September 18-20; Delft, Netherland.

[12] M. A. Boden, Creativity and Arts: Three Roads to Surprise, Oxford University Press, (2012) 